\title{
Parkinson Hastalarının Dikkat Fonksiyonlarının Cinsiyet Açısından Değerlendirilmesi: Bir fMRG Çalıșması
}

\author{
Nur Yılmaz ${ }^{1 *}$, Güzin Özmen ${ }^{2}$ \\ ${ }^{1 *}$ Selçuk Üniversitesi, Teknoloji Fakültesi, Biyomedikal Mühendisliği Bölümü, Konya, Türkiye, (ORCID: 0000-0001-7491-1219), nuryilmaz66@gmail.com \\ ${ }^{2}$ Selçuk Üniversitesi, Teknoloji Fakültesi, Biyomedikal Mühendisliği Bölümü, Konya, Türkiye (ORCID: 0000-0003-3007-5807), gozmen@selcuk.edu.tr
}

(1st International Conference on Applied Engineering and Natural Sciences ICAENS 2021, November 1-3, 2021)

(DOI: 10.31590 /ejosat.1011593)

ATIF/REFERENCE: Yılmaz, N. \& Özmen, G. (2021). Parkinson Hastalarının Dikkat Fonksiyonlarının Cinsiyet Açısından Değerlendirilmesi: Bir fMRG Çalışması. Avrupa Bilim ve Teknoloji Dergisi, (28), 843-848.

\section{Öz}

Titrek felç olarak tanımlanan Parkinson hastalığı Alzheimer'dan sonra en sık görülen 2. nörolojik hastalıktır. Son yıllarda, Parkinson hastalığının titreme, depresyon, duruş bozukluğu gibi farklı belirtileriyle ilişkilendirilen çalışmalar yapılmıştır. Bu çalışmada Parkinson hastalarındaki dikkat bozukluğu üzerinde durulmuştur. Dikkat bozukluğu, Parkinson hastalığı olan bireylerde yaygın olarak bulunur ve bireylerin yaşam kalitesi üzerinde önemli bir etkisi vardır. Dikkatin uyarma, yönlendirme ve yürütme etkilerini tek görevde birleştiren Dikkat Ağ Testi, 25 Parkinson hastası ve 21 sağlıklı birey tarafindan uygulanmış ve görev tabanlı fonksiyonel görüntüleme tekniği ile kaydedilmiş̧ir. Kaydedilen veriler kafa hareketlerinin düzenlenmesi, işlevsel-yapısal bağdaştırma, segmentasyon, normalleştirme ve bulanıklaştırma ile bir dizi ön işleme aşamasından geçirilmiş ve etki kontrastları oluşturulmuştur. Oluşturulan kontrastlar ile grup analizleri yapılmış ve aktivasyon sonuçları karşılaştırılmıştır. Parkinson hastası ve sağlıklı bireylerin aktivasyonlarına bakıldığında her iki grup için Frontal ve Parietal bölgelerde aktivasyonun yoğunlaştı̆̆ı, fakat Parkinson hastalarının dikkatin her etkisi için belirgin aktivasyon yoğunluğuna sahip olduğu görülmüştür. Bu çalışmada aynı zamanda Parkinson hastalarındaki dikkat bozukluğunun cinsiyet üzerindeki etkisi de araştırılmıştır. Parkinsona sahip 7'si kadın 18'i erkek toplam 25 bireyin aktivasyon sonuçları karşılaştırılmıştır. Erkek bireylerin kadın bireylere kıyasla uyarma ve yönlendirme etkilerinde, Frontal ve Oksipital bölgelerde belirgin aktivasyon farklarına sahip olduğu görülmüştür. Bu aktivasyon farklarından hareketle Parkinson hastalığına sahip erkek bireylerin görsel bilgiyi işleme ve dikkati yönlendirme becerileri kadın bireylere kıyasla daha başarılı olduğu görülmüştür.

Anahtar Kelimeler: Parkinson Hastalı̆̆

\section{Gender-Assessment of Attention Functions in Parkinson's Patients: An fMRI Study}

\begin{abstract}
Parkinson's disease, defined as shaky palsy, is the second most common neurological disease after Alzheimer's. In recent years, studies have been carried out that relate different symptoms of Parkinson's disease such as tremor, depression, and postural disorder. In this study, attention disorder in Parkinson's patients was focused on. Attention deficit is commonly found in individuals with Parkinson's disease and has a significant impact on individuals' quality of life. The Attention Network Test, which combines the alerting, orienting and executive effects of attention in a single task, was administered by 25 Parkinson's patients and 21 healthy individuals and recorded with the task based functional imaging technique. The recorded data were preprocessed through a series of preprocessing steps with realignment, coregistration, segmentation, normalization and smoothing, and effect contrasts were created. Group analyzes were made with the created contrasts and the activation results were compared. When the activations of Parkinson's patients and healthy individuals were examined, it was seen that the activation intensified in the frontal and parietal regions for both groups, but Parkinson's patients had a significant activation intensity for each effect of attention. In this study, the effect of attention disorder in Parkinson's patients on gender was researched. The activation results of a total of 25 individuals, 7 female and 18 male, with Parkinson's were compared. It has been observed that male individuals have significant activation differences in the frontal and occipital regions in their excitation and orientation effects compared to female individuals. Based on these activation differences, it was observed that male individuals with Parkinson's disease were more successful in processing visual information and directing attention skills than female individuals.
\end{abstract}

Keywords: Parkinson's Disease, fMRI, Attention Network Test.

\footnotetext{
*Sorumlu Yazar: nuryilmaz66@gmail.com
} 


\section{Giriş}

Parkinson hastalığı ilk kez 1817 yılında Doktor James Parkinson tarafından "titrek felç" olarak tanımlanmıştır (Palsy, 2015) . 60'lı yaşlarda görülmeye başlayan hastalık yaş ilerledikçe belirtilerini arttırır. Nörolojik bir hastalık olan Parkinson, Alzheimer'dan sonra en sık görülen 2. hastalıktır (De Lau, 2006). Beynin arka tarafina uzanan "substansiya nigra" adı verilen siyah pig-mentli bölgenin etkinliğinin azalması sonucu "dopamin" salgılanması azalarak belirtilerin çıkmasına sebep olur (Ece Akbayır, 2017). Parkinson hastalığının teşhisi için özel bir test yoktur. Diğer hastalık olasılıklarının elenmesi ya da hastanın Parkinson ilaçlarına yanıt vermesi durumunda teşhis konulur (Jankovic., 2008). Tremor (titreme), rijidite (dinlenme halinde kasların sert ve gergin olma durumu), bradikinezi (hareketlerde yavaşlama) ve duruş refleks bozukluğu bu hastalığın temel belirtileriyken görme bozukluğu, depresyon, uyku bozukluklarıyla da ilişkilendirilen çalışmalar yapılmıştır (Price, 1992), (Ahn, 2018), (Lemke, 2004), (Factor, 1990).

Fonksiyonel Manyetik Rezonans Görüntüleme (fMRG), dinlenme durumu ya da görev tabanlı bir görüntüleme tekniğidir. Kan-oksijen düzeyindeki değişimin (Blood Oxygeneration Level Dependent (BOLD)), beyinde oluşturduğu nöral aktivitenin dolaylı olarak ölçümünü sağlar (Logothetis, 2008). Bir görev ya da dinlenme durumunda beynin aktif bölgesi diğer bölgelere kıyasla daha fazla oksijene ihtiyaç duyar. $\mathrm{Bu}$ ihtiyaca cevap olarak aktif bölgeye daha fazla kan akışı olur. Beynin aktif bölgelerdeki deoksihemoglobin artışı ile ölçülen sinyal değişiklikleri beynin fonksiyonel haritalanmasına imkan verir.

Son zamanlarda nörodejeneratif hastalıklara (Alzheimer, Parkinson, Motor Nöron Hastalıkları...) ilişkin fMRG çalışmalarına bakıldığında, sonuçların hastaların beyin aktivasyonlarının sağlıklı bireylere kıyasla ayırıcı nitelikler gösterdiği saptanmıştır (Wang, 2007), (Shine, 2015).

Dikkat bozukluğu, demansı olmayan Parkinson hastalığı (PH) olan kişilerde yaygın olarak görülür (D. Aarsland, 2010). Literatüre bakıldığında PH'de dikkat bozukluğunun araştırılmasına ilişkin yapılan birkaç çalışmada Dikkat A ̆ Testi (DAT) kullanılmıştır (Vandenbossche, 2012), (Hall, 2016), (Madhyastha, 2015), (Boord, 2017). Boord ve ark. PH ve sağlıklı bi-reyler (SB) arasında dikkat fonksiyonu farklılıklarını analiz etmişlerdir. PH'ye sahip bireylerde, dorsal dikkat ve frontoparietal ağların dört bölgesinde (sağ frontal göz alanı, sol ve sağ intraparietal sulkus ve precuneus) artan yürütme zorluğu sırasında daha fazla aktivasyon görülmüştür (Boord, 2017). Madhyastha ve ark. PH'ye sahip bireylerin dikkat ağlarını destekleyen kortikal bölgelerinin erken etkilendiği, aynı zamanda uyaranlara daha yavaş cevap verdiği göz-lenmiştir (Madhyastha, 2015).

Literatürde PH'ye sahip bireylerin cinsiyete dayalı farklılıklarının araştırıldığı çalışmalar mevcuttur (Ophey, 2018), (Lee, 2020). Bu çalışma da Parkinson hastalarının dikkat fonksiyonlarını cinsiyet açısından değerlendirmeyi amaçlamaktadır. Boord ve ark. tarafindan oluşturulan veri seti kullanılmıştır (Grabowski, 2019). Veriler bir dizi ön işleme aşamasından geçirildikten sonra rastgele etki (random effect) grup analizi yapılarak soçnuçlar karşılaştırılmıştır.

\section{Materyal ve Metot}

\subsection{Katılımcılar}

Bu çalışmadaki görev tabanlı fMRG verileri, daha büyük bir veri setinden seçilerek kamuya açık olarak paylaşılan ANT: Healthy Aging and Parkinson's Disease veri setinden elde edilmiştir (Grabowski, 2019). Çalışma-ya 1-3 hafta arayla iki tarama seansına katılan Par-kinson hastası (PH) 25 birey ve 21 sağlıklı birey (SB) dahil edilmiştir. PH verileri, kapsamlı klinik muayene ve nöropsikolojik değerlendirmeye tabi tutuldukları daha büyük bir çalışma grubundan alınmıştır (Cholerton BA, 2013).

Tablo 1. Demografik Bilgiler

\begin{tabular}{l|c|c}
\hline & PH & SB \\
\hline Katılımcı Sayısı & 25 & 21 \\
\hline Yaş (Yıl) & $66.1(10.0)$ & $62.1(9.9)$ \\
\hline Cinsiyet (Erkek Sayısı) & 18 & 9 \\
\hline Hoehn \& Yahr & $2.0(0.3)$ & \\
\hline UPDRS I & $10.0(5.7)$ & \\
\hline UPDRS II & $8.8(5.3)$ & \\
\hline UDPRS III & $23.6(8.7)$ & \\
\hline UPDRS IV & $2.0(3.7)$ & \\
\hline Hastalık Başlangıcı (Yıl) & $8.4(4.8$ & \\
\hline Eğitim (Yıl) & $16.2(2.1)$ & $15.9(2.4)$ \\
\hline El Kullanımı (Săg) & 21 & 20 \\
\hline
\end{tabular}

Veriler, 32 kanallı SENSE baş bobini ile Philips 3.0T X-Serisi Achieva MR Sistemi (Philips Medical Systems, yazılım sürümü R2.6.3) kullanılarak elde edilmiştir. Her birey DAT görevini altı kez tekrarlamış ve elde edilen işlevsel ve T1 ağırlıklı yapısal taramalar kaydedilmiştir. Toplamda 46 bireyin her iki oturumda da altı görev taraması ile veriseti oluşturulmuştur.

Çalışmada kullanılan veri setinde görev taramaları için, tüm beyin eksenel eko-düzlemsel görüntüler (EPI) (43 siralı artan dilim, $3 \mathrm{~mm}$ izotropik voksel, görüş alanı=240x240x129 mm, tekrar süresi $=2400 \mathrm{~ms}$, yankı süresi $=25 \mathrm{~ms}$, çevirme açısı $=79^{\circ}$, SENSE ivme faktörü=2) AC-PC hattına paralel olarak toplanmıştır. Her fonksiyonel tarama 149 kesitten (5.96 dakika) oluşmaktadır. Kayıt ve doku analizleri için $1 \mathrm{~mm}$ izotropik voksellere sahip bir sagital T1 ağırlıkl 3D MPRAGE (176 kesit, matris boyutu $=256 \times 256$, ters çevirme süresi $=1100 \mathrm{~ms}$, turbo alan yankı faktörü $=225$, tekrar süresi $=7,46 \mathrm{~ms}$, yankı süresi $=3,49 \mathrm{~ms}$, çevirme açısı $=7^{\circ}$, atış aralığ $1=2530 \mathrm{~ms}$ ) elde edilmiştir

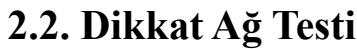

Fan ve ark. dikkatin davranışsal ölçümünü sağlamak için bir dikkat ağı testi (DAT) geliştirmişlerdir (J. Fan B. M., 2002). DAT, dikkatin uyarma, yönlendirme ve yürütme işlevlerinin beyin aktivitesini tek görevde inceleme imkânı sunar.

Test esnasında katılımcılara ilk olarak 200ms boyunca ekranın merkezinde bulunan sabitleme noktası (işaret yok), sabitleme noktası üzerinde işaret (merkez işaret) ya da sabitleme noktası altında veya üstünde işaret (konumsal işaret) gösterilmiştir. Ardından 300-11800 ms aralığında değişken bir sürede sabitleme ekranı gösterilmiştir. Son olarak 2000 ms'yi geçmeyecek şekilde merkezdeki ok ile aynı (uyumlu) ya da zıt (uyumsuz) yönlü olarak 5 adet ok gösterilmiş ve katılımcının merkezdeki okun yönüne göre sağ veya sol elindeki düğmeye basması istenmiştir. DAT şeması Şekil 1'de görülmektedir. 


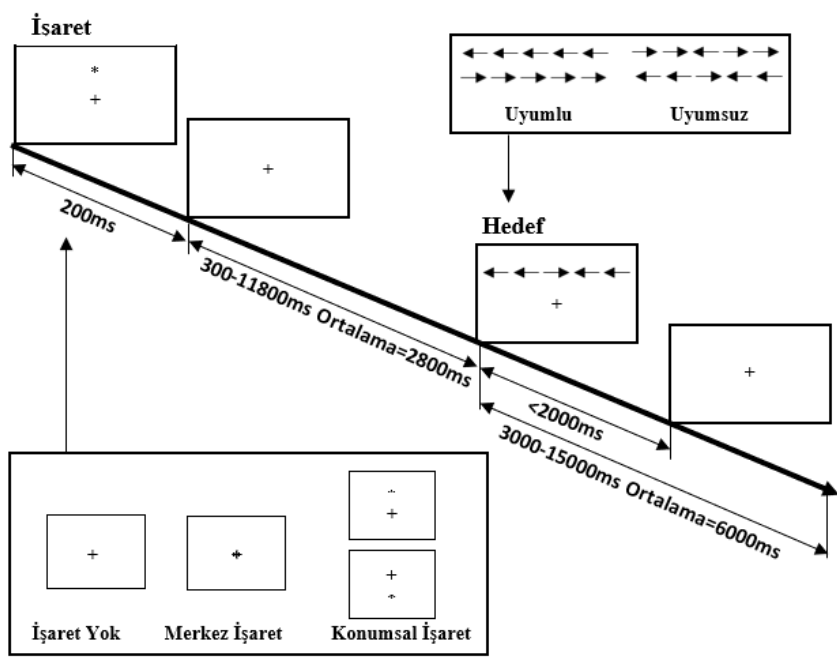

Şekil 1. Dikkat Ă̆ Test Şeması (J. Fan B. M., 2002)

fMRG kontrastları oluşturmak için üç işaret koşulu (işaret yok, merkez işaret, konumsal işaret) ve iki hedef koşul (uyumlu ve uyumsuz) kullanılmıştır. Oluşturulan davranışsal kontrastlar aşağıdaki gibidir.

- Uyarı etkisi=İşaret yok yanıtı-Merkez işaret yanıtı

- Yönlendirme etkisi=Merkez işaret yanıtı-Konumsal işaret yanıtı

- Yürütme etkisi=Uyumsuz hedef yanıtı-Uyumlu hedef yanit1

\section{3. Önişleme}

Fonksiyonel MR görüntüleri ile istatistiksel analiz yapılabilmesi için verilere önişleme adımlarının uygulanması gerekmektedir. Bunlar, kafa hareketlerinin düzenlenmesi, işlevsel-yapısal bağdaştırma, segmentasyon, normalleştirme ve bulanıklaştırma işlemlerinden oluşmaktadır. Bu çalışmada görev tabanlı verilerin önişlemesi Matlab tabanlı SPM12 (Statistical Parametric Mapping) arayüzü kullanılarak gerçekleştirilmiştir.

Kafa Hareketlerinin Düzeltilmesi (Realignment): Ön işlemenin ilk adımı işlevsel görüntüleri yeniden hizalamaktır. Görüntü kalitesini negatif açıdan etkileyen ve kafa hareketlerinden kaynaklanan gürültünün filtrelenmesi gerekir. $\mathrm{Bu}$ aşamada her bir dilim tek bir referans hacmiyle bağdaşacak şekilde hizalanır.

İşlevsel ve Yapısal Bağdaştırma (Coregistration): Kafa hareketi düzeltilen görüntüler katılımcının T1 ağırlıklı görüntüsü ile bağlanır. Bu aşamada beyin aktivasyonlarının nöroanatomi ile bağlantısı sağlanır.

Segmentasyon: Beynin anatomik yapısı gri madde, beyaz madde ve beyin omurilik sıvısı (BOS) olarak ayırılır.

Normalleştirme: Yüksek çözünürlüklü T1 ağırlıklı görüntüleri, standart $\mathrm{T} 1$ beyin şablonu ile standartlaştırılır. Hesaplanan normalizasyon parametreleri standartlaştırılan görüntülere uygulanır. Bu adımda amaç fonksiyonel görüntülerin standardize edilerek aynı boyut ve şekilde olmasını sağlayarak bireyler arası karşılaştırmaya imkân sağlanmasıdır.

Bulanıklaştırma (Smoothing): Önişlemenin son adımıdır. Hafif fonksiyonel/anatomik farklılıklarıdüzeltmek amacıyla uygulanmaktadır. Bulanıklaştırma işlemi bir kernel çekirdeğinin görüntü üzerinde gezdirilmesi ile gerçekleşir. Bu çalışmada FWHM (Full Width at Half Maximum (Yarı Maksimumda Tam Genişlik)) kernel çekirdeğinin boyutu $4 \mathrm{~mm}$ olarak seçilmiştir.

\subsection{Veri Analizi}

$\mathrm{Bu}$ çalışmada fMRG verilerinin istatistiksel analizi için Genel Doğrusal Modele (General Lineer Models (GLM)) dayalı bir yaklaşım uygulanmıştır. Kontrast vektör oluşturmak için üç işaret koşulu (işaret yok, merkez işaret, konumsal işaret) ve iki hedef koşul (uyumlu ve uyumsuz) başlangiç süreleri belirtilerek tanımlanmış ve aktif durumlar için +1 ve pasif durumlar için -1 kontrast ağırlıkları belirlenmiş, hata denemeleri analize dahil edilmemiştir. Görev tabanlı fonksiyonel verilere $128 \mathrm{~Hz}$ yüksek geçirgen filtre uygulanmıştır. Her katılımcı için ayrı ayrı uyarma, yönlendirme ve yürütme kontrast vektörleri oluşturulmuştur. Oluşturulan kontrastların anlamlılık seviyesi $\mathrm{p}=0.001$ ile eşiklendirilmiştir ve family-wise error (FWE) düzeltmesi yapılmamıştır.

Çalışmada cinsiyet açısından PH'yi değerlendirmek ve grup analizinde kullanmak için öncelikle tüm deneklere bireysel analiz uygulanmıştır. İlk aşamada SB ve PH'ye sahip bireylerin uyarma, yönlendirme ve yürütme etkisine yönelik ayrı ayrı grup analizi yapılmıştır. İstatistiksel grup analizi sonucu oluşan renklendirilmiş beyin haritaları Şekil 2' de uyarma, Şekil 3' de yönlendirme ve Şekil 4'te yürütme etkisi için görülmektedir. İkinci olarak PH' ye sahip bireylerde DAT görevlerinin cinsiyet yö-nünden karşılaştırmalı grup analizi gerçekleştirilmiş ve meydana gelen aktivasyonlar, beyin bölgesi ve voksel sayıları belirtilerek tablolaştırılmıştır. Kadın ve erkek PH'ler için elde edilen renklendirilmiş beyin haritaları Şekil 5' te uyarma, Şekil 6'da yönlendirme ve Şekil 7'de yürütme etkisi için görülmektedir. 


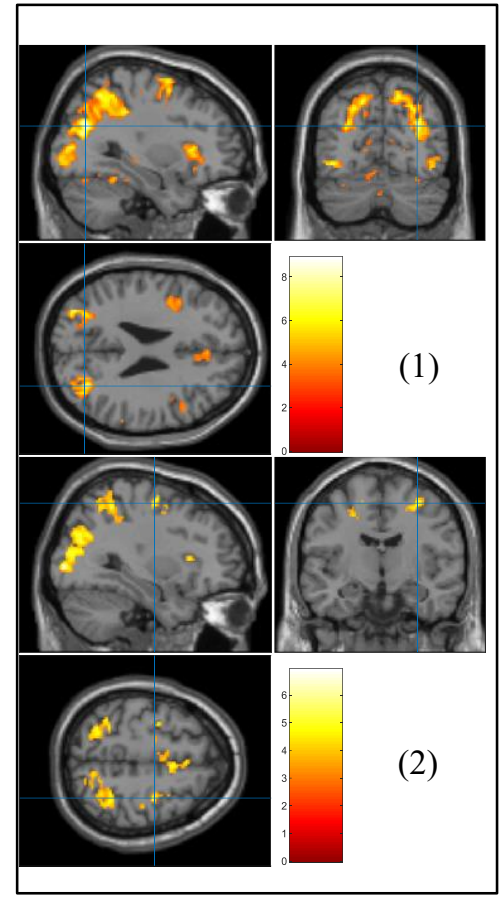

Şekil 2. $P H$ (1) ve $S B$ (2) Uyarma Etkisi

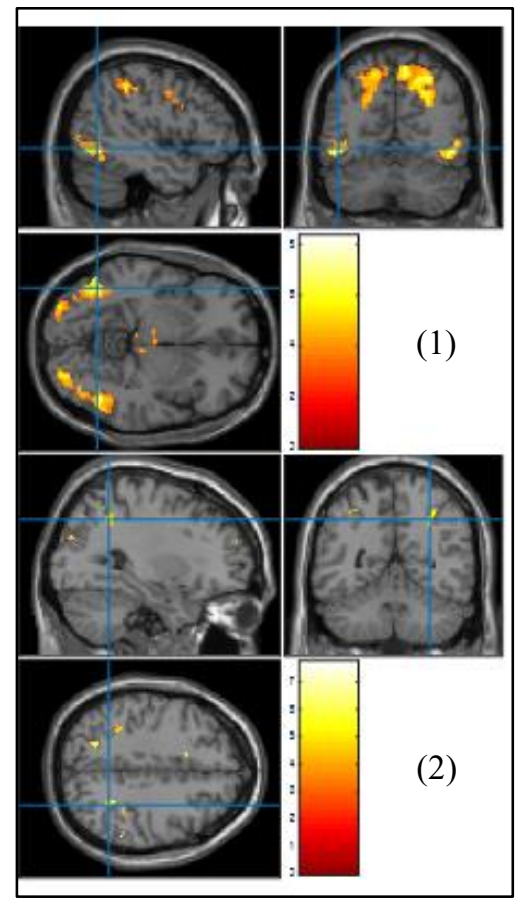

Şekil 5. PH Erkek (1) ve PH Kadın (2) Uyarma Etkisi

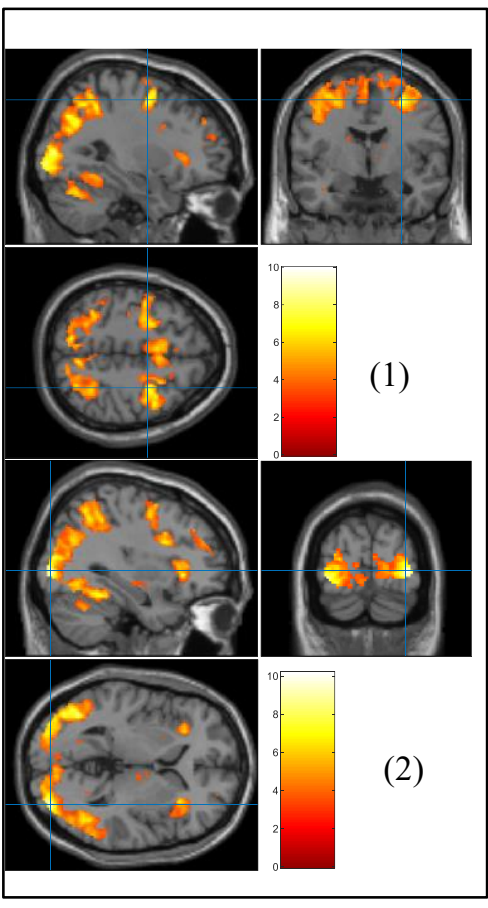

Şekil 3. $P H$ (1) ve $S B$ (2) Yönlendirme Etkisi

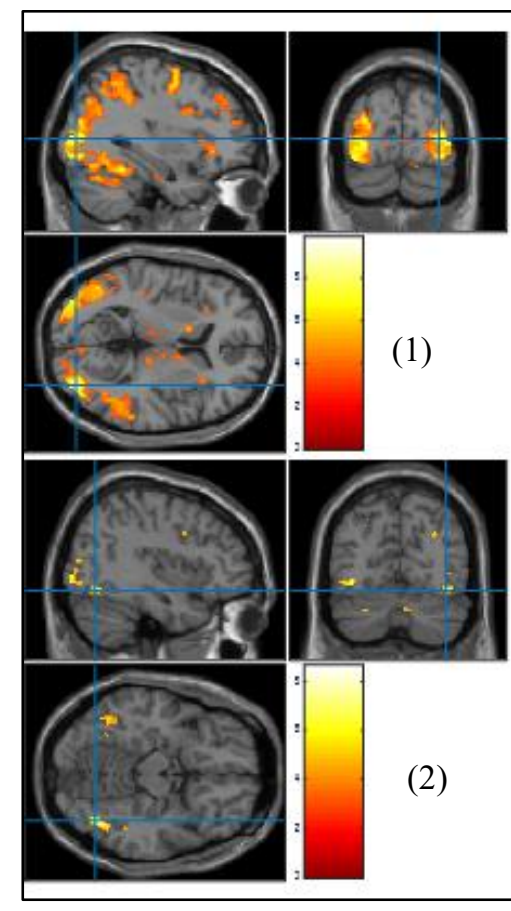

Şekil 6. PH Erkek (1) ve PH Kadın (2) Uyarma Etkisi

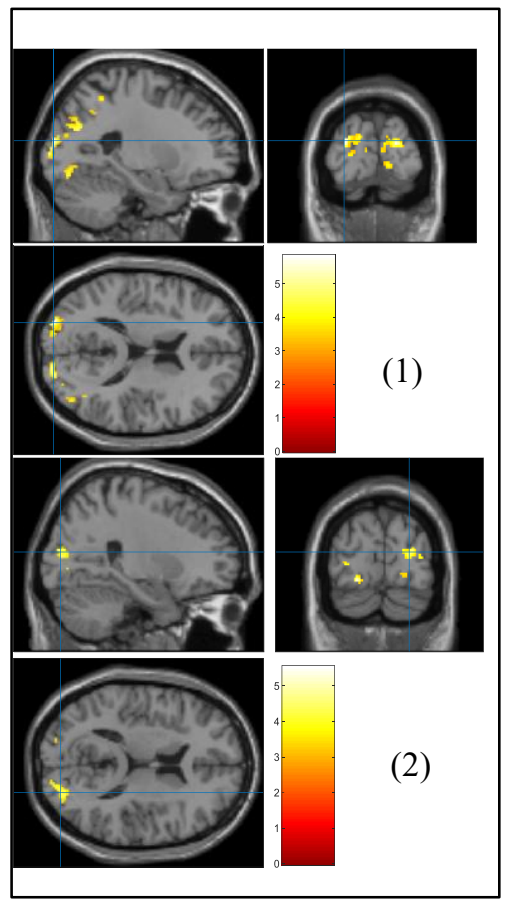

Şekil 4. PH (1) ve SB (2) Yürütme Etkisi

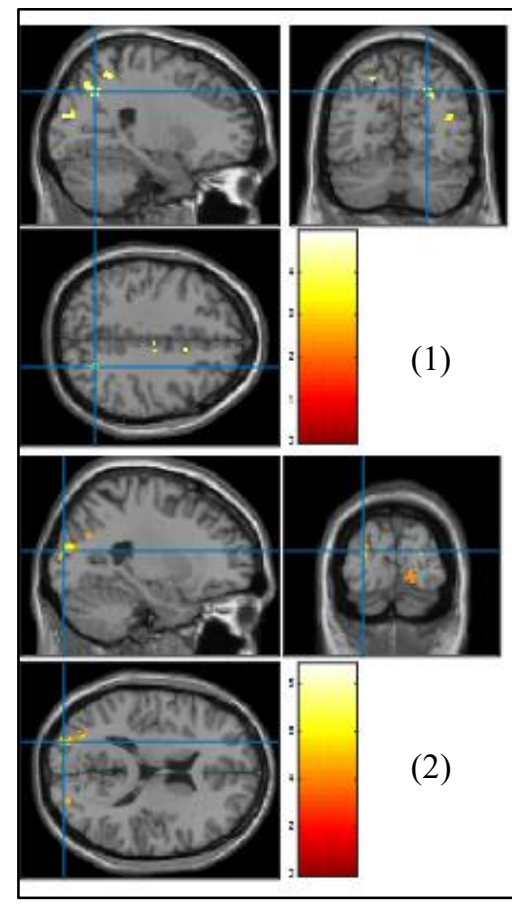

Sekil 7. PH Erkek (1) ve PH Kadın (2) Uyarma Etkisi 
Tablo 3. PD'ye sahip kadın bireylerin DAT görevleri aktivasyon tablosu ( $p<0.001$ (FWE düzeltilmemiş), $T=$ Eşik Yüksekliği)

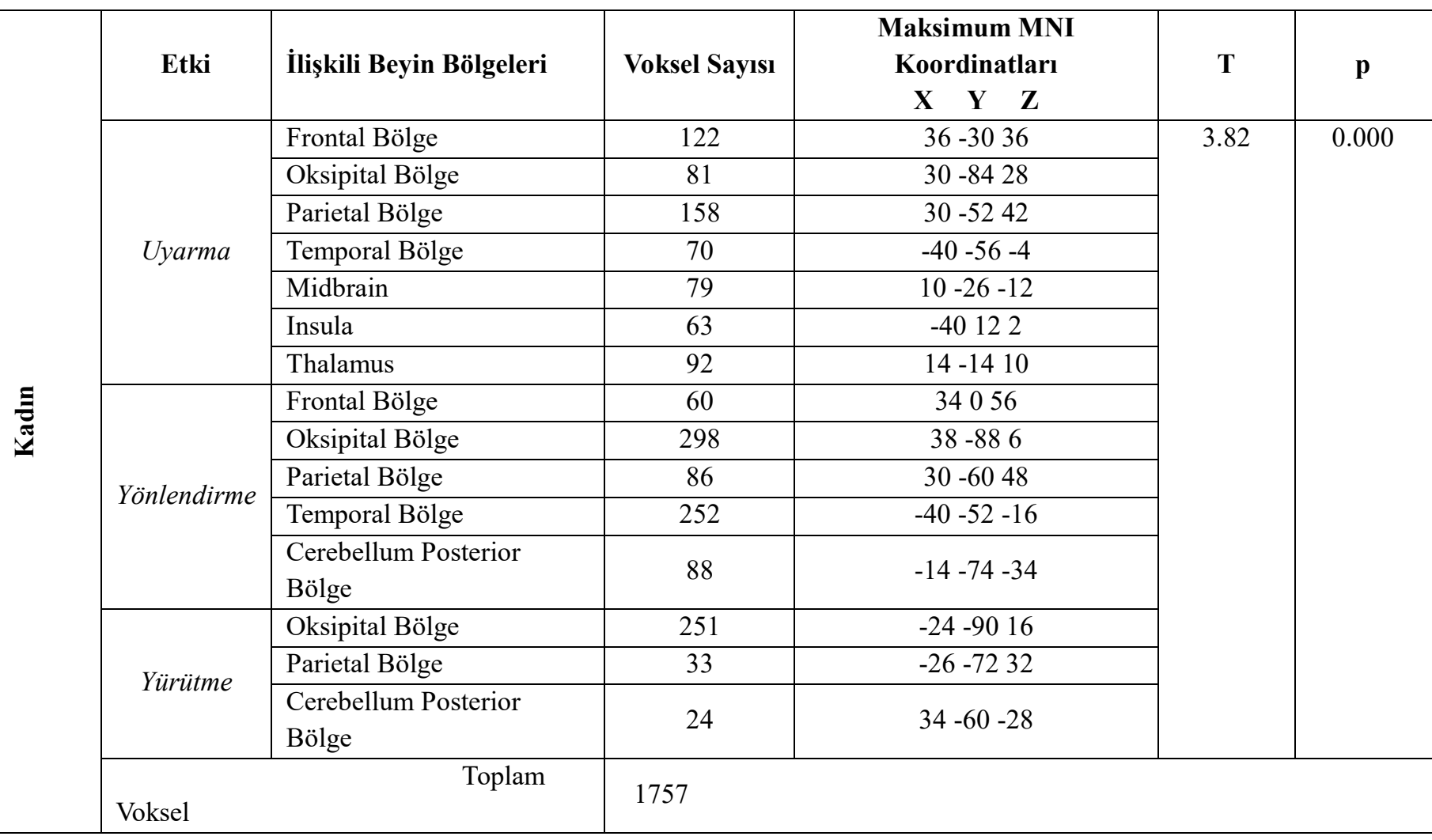

Tablo 4. PD'ye sahip erkek bireylerin DAT görevleri aktivasyon tablosu ( $p<0.001$ (FWE düzeltilmemiş), $T=$ Eşik Yüksekliği)

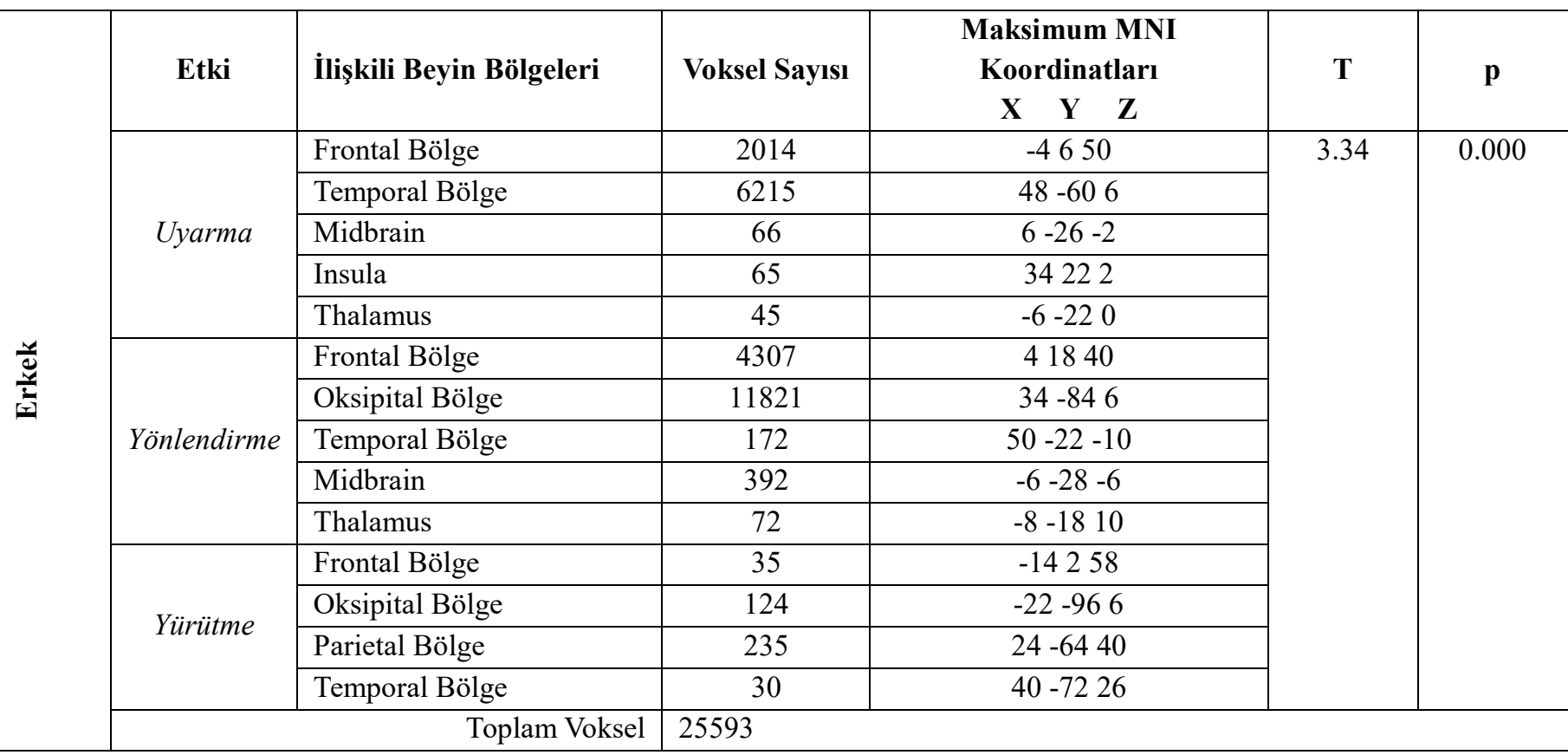

\section{Araştırma Sonuçları ve Tartışma}

\subsection{Sonuç}

Bu çalışmada 21 SB ve 25 PH'li bireyin DAT görevleri esnasındaki fonksiyonel MR taramaları kul-lanılarak grup analizi yapılmış ve sonrasında $\mathrm{PH}^{\prime}$ ye sahip 7 kadın ve 18 erkek birey e-ISSN: 2148-2683 arasında beyin aktivasyon farkları açısından cinsiyet karşılaştırması gerçekleştirilmiştir.

Üç farklı dikkat görevi için karşılaştırma yapıldığında SB'nin PH'ye sahip bireylere nispeten uyar-ma ve yürütme görevlerinde aktivasyon farklılıkları görülmüştür. Boord ve ark. yaptıkları çalışmada Parkinson hastası ve sağlıklı bireyler arasında beyin 
aktivasyon farklarını incelemişler ve özellikle yürütme etkisi için Parkinson hastalığına sahip bireylerde Oksipital, Frontal ve Parietal bölgelerde yüksek aktivasyon oluştuğunu tespit etmişlerdir (Boord, 2017). Benzer şekilde bu çalışmada da her iki grup içinde aktivasyonların Frontal ve Parietal bölgelerde yoğunlaştı̆̆1 görülmüştür.

PD'ye sahip bireylerin cinsiyet karşılaştırmasına bakıldığında erkek bireyler kadın bireylere göre 23836 voksel daha fazla aktivasyon göstermiştir. Sirasıyla dikkat görevlerinin aktivasyon farklarına bakıldığında, uyarma etkisinin frontal ve temporal bölgelerde belirgin aktivasyon farkı görülürken, midbrain, thalamus ve insula ortak aktivasyon bölgelerinde ciddi bir farka rastlanmamıştır.

Yönlendirme etkisinde yine frontal ve oksipital bölgelerde ciddi aktivasyon farklılıkları görülürken, erkek bireylerde farklı olarak midbrain ve thalamusta aktivasyonlar görülmüştür.

Yürütme etkisinde oksipital ve parietal bölgelerde aktivasyon farklılıkları görülmüştür. Özellikle uyarma ve yönlendirme etkilerinde frontal ve oksi-pital bölgelerde ciddi aktivasyon farkları görülmüş-tür.

Bu sonuçlara göre PH'ye sahip erkek bireylerin görsel bilgiyi işleme ve dikkati yönlendirme becerileri kadın bireylere kıyasla daha başarılı olduğu sonucuna varılabileceği görülmektedir.

\subsection{Tartışma}

Bu çalışmada kullanılan veri setinde hem SB ve hem PH için kadın-erkek birey sayısında orantısız-lık mevcuttur.

Kullanılan veri seti ile yapılan çalışmalara bakıldı-ğında SB ve PH'ye sahip bireylerin DAT görevler boyunca verilen yanıt gecikmeleri karşılaştırılmış ve PH'ye sahip bireylerin SB'ye oranla yanıtlarında gecikmeler saptanmıştır (Madhyastha, 2015). Ayrıca yapılan diğer çalışmada PH'ye sahip bireylerin beyin aktivasyonlarında yürütme etkisinin SB'ye göre yüksek aktivasyon oluşturduğu görülmüştür (Boord, 2017). Bu çalışma ise PD'ye sahip bireylerin dikkat eksiklikliğinin, DAT görevleri ile cinsiyet açısından farklılığını an-lamaya yönelik bir adımı temsil etmektedir.

\section{Kaynakça}

Ahn, J. L. (2018). Retinal thinning associates with nigral dopaminergic loss in de novo Parkinson disease. . Neurology, 91(11), e1003-e1012.

Boord, P. M. (2017). Executive attention networks show altered relationship with default mode network in PD. . NeuroImage: Clinical(13), 1-8.

Cholerton BA, Z. C. ( 2013). Pacific Northwest Udall Center of excellence clinical consortium: study design and baseline cohort characteristics. . J Parkinsons Dis., 3(2), 205-214.

D. Aarsland, K. B.-G. (2010). Mild cognitive impairment in Parkinson disease: a multicenter pooled analysis. Neurology(75), 1062-1069.

De Lau, L. M. (2006). Epidemiology of Parkinson's disease. The Lancet Neurology, 5(6), 525-535.

Ece Akbayır, M. Ş. (2017). PARKINSON HASTALIĞININ ETYOPATOGENEZİ. DENEYSEL TIP DERGISI, 7(13).

Factor, S. A.-R. (1990). Sleep disorders and sleep effect in Parkinson's disease. . Movement disorders: official journal of the Movement Disorder Society, 5(4), 280-285.
Grabowski, T. K. (2019). ANT: Healthy aging and Parkinson's disease.

OpenNeuro. https://doi.org/10.12688/f1000research.19288.1 adresinden alınd 1

Hall, J. M. (2016). Dysfunction in attentional processing in patients with Parkinson's disease and visual hallucinations. . Journal of Neural Transmission(123(5)), 503-507.

J. Fan, B. M. (2002). Testing the efficiency and independence of attentional networks. J. Cogn. Neurosci.(14 (3)), 340-347.

J. Fan, B. M. (2005). The activation of attentional networks. NeuroImage(26), 471-479.

Jankovic., ]. J. (2008). Parkinson's disease: clinical features and diagnosis. Journal of neurology, neurosurgery \& psychiatry, 4(79), 368-376.

Lee, Y. H. (2020). Gender-specific effect of urate on white matter integrity in Parkinson's disease. Parkinsonism \& Related Disorders, , 75,41-47.

Lemke, M. R. (2004). Depression and Parkinson's disease. . Journal of neurology, 251(6), vi24-vi27.

Logothetis, N. K. (2008). What we can do and what we cannot do with fMRI. . Nature(453(7197)), 869-878.

Madhyastha, T. M. (2015). Dynamic connectivity at rest predicts attention task performance. Brain connectivity (5(1)), 45-59.

Ophey, A. E. (2018). Health-related quality of life subdomains in patients with Parkinson's Disease: The role of gender. . Parkinson's Disease.

Palsy, S. (2015). James Parkinson's essay on the shaking palsy. JR Coll Physicians Edinb(45), 84-6.

Price, M. J. (1992). Abnormalities in color vision and contrast sensitivity in Parkinson's disease. Neurology, 42(4), 887-887.

Shine, J. M. (2015). Abnormal connectivity between the default mode and the visual system underlies the manifestation of visual hallucinations in Parkinson's disease: a task-based fMRI study. npj Parkinson's Disease, 1(1), 1-8.

Vandenbossche, J. D. (2012). Conflict and freezing of gait in Parkinson's disease: support for a response control deficit. Neuroscience( 206), 144-154.

Wang, K. L. (2007). Altered functional connectivity in early Alzheimer's disease: A resting-state fMRI study. Human brain mapping, 28(10), 967-978. 